\title{
Carboxyhaemoglobin and plasma thiocyanate: complementary indicators of smoking behaviour?
}

\author{
Y SALOOJEE, CJ VESEY, PV COLE, MAH RUSSELL \\ From the Department of Anaesthetics, St Bartholomew's Hospital, London, and the Addiction Research \\ Unit, Institute of Psychiatry, London
}

\begin{abstract}
Carboxyhaemoglobin and plasma thiocyanate concentrations were measured in 79 non-smokers and 360 cigarette smokers. The mean levels were $0.73 \%$ and $7.09 \%$ carboxyhaemoglobin and 40.2 and $133.8 \mu \mathrm{mol}$ thiocyanate/l plasma respectively. With $1.6 \%$ carboxyhaemoglobin and $73.0 \mu \mathrm{mol}$ thiocyanate/l plasma as critical values the concentrations of carboxyhaemoglobin in $96.6 \%$ of subjects and of thiocyanate in $93.4 \%$ were compatible with reported smoking status. This difference between the two tests is significant $(p<0.005)$. Statistical combination of the carboxyhaemoglobin and thiocyanate results, with the use of linear discrimination analysis, only marginally improved their diagnostic efficiency $(96.8 \%$ of subjects were grouped correctly). This analysis did, however, successfully regroup 21 of 26 individuals with contradictory carboxyhaemoglobin and thiocyanate classifications. It is concluded that in this study determination of thiocyanate added little to the information obtained from carboxyhaemoglobin measurements alone.
\end{abstract}

Twenty to thirty-five per cent of smokers attending clinics and claiming to have stopped smoking have been shown not to have done so. ${ }^{1-4}$ Consequently, to assess the impact of antismoking strategies biochemical tests are being increasingly used as an independent validation of such claims. Unfortunately even with these tests some smokers and nonsmokers cannot be distinguished with certainty. Vogt $^{5}$ has suggested that discrimination between the groups may be improved by combining two of the tests-namely, estimation of alveolar carbon monoxide and serum thiocyanate. Indeed, he reported that when the two measurements agreed $99 \%$ of the predictions proved correct. In one-tenth of his population, however, the two tests disagreed and assigned subjects to opposite groups. In these instances a means of interpreting the contradictory results is necessary or the tests become meaningless. No such method has yet been suggested.

We have reassessed the ability of carboxyhaemoglobin and plasma thiocyanate estimations to distinguish between smokers and non-smokers, and have also used the statistical technique of discriminant analysis to weight these measures to predict the group to which subjects with conflicting values are most likely to belong.

Address for reprint requests: Dr CJ Vesey, Anaesthetics Laboratory, St Bartholomew's Hospital, 38 Little Britain, London EC1A 7BE.

\section{Methods}

All the subjects were volunteers who had no reason to conceal their true smoking habits. They were smoking and non-smoking members of staff of St Bartholomew's Hospital and smokers attending the addiction research unit at the Maudsley Hospital. The subjects were assigned to one of two groups on the basis of their reported smoking habits. The first group consisted of 360 cigarette smokers (178 men and 182 women) who had not altered their usual smoking behaviour. In the second group there were 79 non-smokers (51 men and 28 women).

Venous blood was taken from each subject, usually in the afternoon or late morning, into a heparinised syringe and kept at $4^{\circ} \mathrm{C}$. Carboxyhaemoglobin was measured within 48 hours with an IL282 CO-Oximeter, the accuracy of which was crosschecked with a gas chromatographic method. ${ }^{6}$ The remaining blood was centrifuged and the plasma separated and stored at $-20^{\circ} \mathrm{C}$ until analysed for thiocyanate. In this estimation plasma $(0.5 \mathrm{ml})$ was mixed with $5 \%$ trichloracetic acid $(4.5 \mathrm{ml})$ and the thiocyanate measured in the protein-free supernatant by an automated modification of the Aldridge technique. ${ }^{78}$ All carboxyhaemoglobin and thiocyanate estimations were performed in duplicate. Statistical calculations were made on the ICL 2980 com- 
puter at Queen Mary College, London. The linear discrimination function (" $z$ ") was calculated as described by Armitage. ${ }^{9}$

\section{Results}

The means and standard deviations and ranges of carboxyhaemoglobin and plasma thiocyanate concentrations in the two groups are shown in table 1. After normalisation of the distribution by logarithmic transformation, the upper $95 \%$ confidence limits (mean $+2 \mathrm{SD}$ ) in the nonsmoking group were $2.0 \%$ carboxyhaemoglobin and $78.0 \mu \mathrm{mol} / \mathrm{l}$ plasma thiocyanate respectively. These limits and the alternative values of $1.6 \%$ carboxyhaemoglobin and $73.0 \mu \mathrm{mol} / \mathrm{l}$ plasma thiocyanate were used to separate the population into smoking and non-smoking groups (table 2 ). Since $1.6 \%$ carboxyhaemoglobin and $73.0 \mu \mathrm{mol}$ thiocyanate/l plasma gave fewer misclassifications these values were used in all subsequent analysis.

The figure shows the scatter of carboxyhaemoglobin $(\mathrm{COHb})$ versus thiocyanate $(\mathrm{SCN})$ values and the line of discrimination based on both measurements $(\mathrm{z}=\log \mathrm{COHb}+0.777 \log \mathrm{SCN})$. The allocation rule would predict that a subject was a smoker if $\mathrm{z}$ was greater than 1.74 and a nonsmoker if it was less than 1.74 . The data were log transformed before this analysis to stabilise the variances in the two groups.

The predictions of the biochemical measurements are compared with the reported smoking habits in table 2 . The carboxyhaemoglobin value and $z$ each gave essentially the same percentage of correct classifications (96.6\% and $96.8 \%$ respectively), which was significantly higher than that achieved with plasma thiocyanate $(93.4 \%, p<0.005)$. The carboxyhaemoglobin and thiocyanate values were in agreement in the classification of $94 \%$ of our population. They placed 26 of the 439 subjects in opposite groups, however; of this number, six had carboxyhaemoglobin levels and 20 had plasma thiocyanate concentrations incompatible with their reported smoking habits. With the use of $z$ four carboxyhaemoglobin and 17 thiocyanate misclassifications were corrected (table 3). Subdividing the smokers into classes according to cigarette consumption shows that errors in prediction are most likely to occur in the light smoking categories (table 4).

\section{Discussion}

To distinguish between smokers and non-smokers an index compound should ideally satisfy the following criteria: (1) be specific for tobacco smoke; (2) be unaffected by genetic, nutritional, or environmental differences; (3) have a long half-life; and (4) be easy to analyse accurately. The most common of such compounds in current use-carbon monoxide, thiocyanate, nicotine, and cotinine-do not completely fulfil these requirements.

Blood or urinary nicotine and cotinine are probably the most specific indicators of smoking available, and while these substances may be detected in non-smokers as a result of passive smoking high concentrations are unusual. ${ }^{1011}$ They both, however, have a shorter half-life than thiocyanate and are not as easy to measure as carboxyhaemoglobin. Furthermore, where chewing gum containing nicotine is

Table 1 Mean ( $\pm S D)$ and range of carboxyhaemoglobin (COHb) and plasma thiocyanate (SCN) concentrations in smokers and non-smokers

\begin{tabular}{|c|c|c|c|c|c|c|c|}
\hline & \multirow[t]{2}{*}{$n$} & \multicolumn{3}{|c|}{$\% \mathrm{COHb}$} & \multicolumn{3}{|c|}{$S C N(\mu \mathrm{mol} / \mathrm{l})$} \\
\hline & & Mean & $\pm S D$ & Range & Mean & $\pm S D$ & Range \\
\hline $\begin{array}{l}\text { Non-smokers } \\
\text { Smokers }\end{array}$ & $\begin{array}{r}79 \\
360\end{array}$ & $\begin{array}{l}0.73 \\
7.09 \\
\end{array}$ & $\begin{array}{l}0.41 \\
2.9\end{array}$ & $\begin{array}{l}0-2 \cdot 3 \\
0 \cdot 3-15 \cdot 5\end{array}$ & $\begin{array}{r}40 \cdot 2 \\
133 \cdot 8 \\
\end{array}$ & $\begin{array}{l}16 \cdot 6 \\
45 \cdot 5\end{array}$ & $\begin{array}{l}14-114 \\
33-287 \\
\end{array}$ \\
\hline
\end{tabular}

Table 2 Percentage of self-reported non-smokers and smokers misclassified on the basis of the specified limiting values of carboxyhaemoglobin (COHb) or plasma thiocyanate (SCN) and by discriminant analysis (z) (subjects with values less than or equal to the cut-off point are considered to be non-smokers)

\begin{tabular}{|c|c|c|c|c|c|}
\hline & \multicolumn{2}{|c|}{ COHb cut-off point (\%) } & \multicolumn{2}{|c|}{ SCN cut-off point ( $\mathrm{\mu mol} / \mathrm{l})$} & \multirow{2}{*}{$\begin{array}{l}z^{*} \\
1 \cdot 74\end{array}$} \\
\hline & $1 \cdot 6$ & $2 \cdot 0$ & $73 \cdot 0$ & $78 \cdot 0$ & \\
\hline $\begin{array}{l}\% \text { non-smokers }(n=79) \\
\% \text { smokers }(n=360) \\
\% \text { all subjects }\end{array}$ & $\begin{array}{l}2.53 \\
3.61 \\
3.42\end{array}$ & $\begin{array}{l}1 \cdot 27 \\
4 \cdot 17 \\
3 \cdot 64\end{array}$ & $\begin{array}{l}5 \cdot 06 \\
6 \cdot 94 \\
6 \cdot 61\end{array}$ & $\begin{array}{l}2 \cdot 53 \\
9 \cdot 44 \\
8 \cdot 20\end{array}$ & $\begin{array}{l}0 \\
3 \cdot 89 \\
3 \cdot 19\end{array}$ \\
\hline
\end{tabular}

${ }^{*} \mathrm{z}=\log \mathrm{COHb}+0.777 \log \mathrm{SCN}$. 


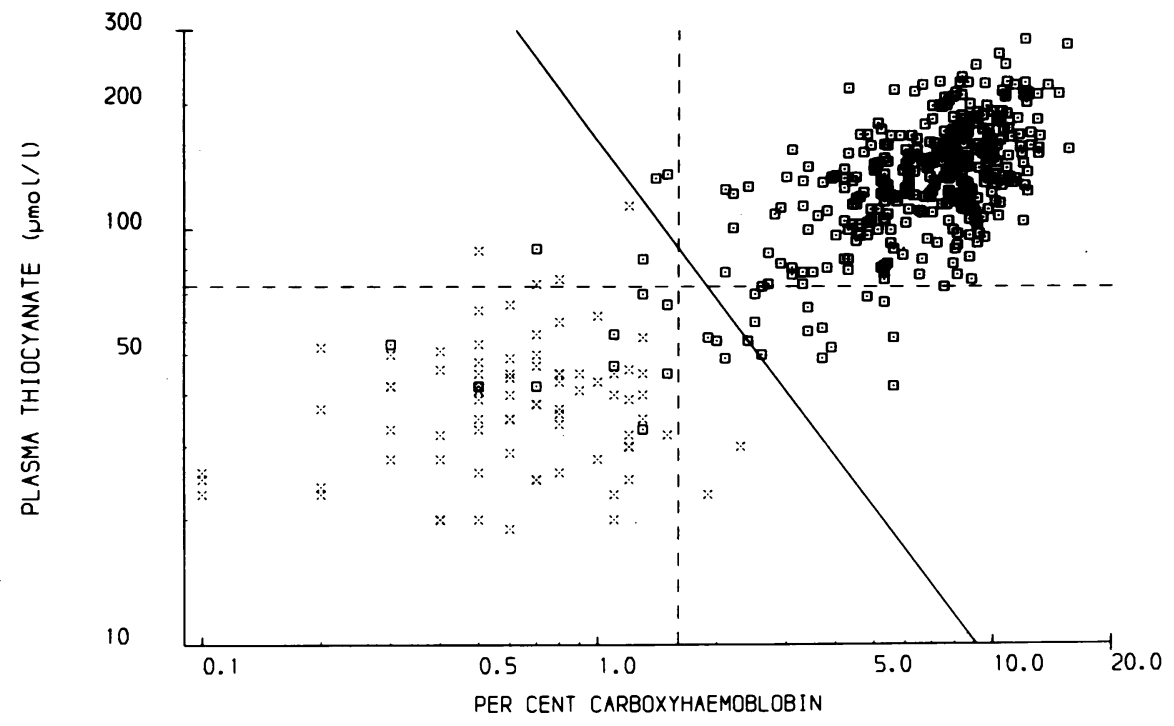

Scatter diagram of carboxyhaemoglobin (COHb) v thiocyanate (SCN) values in 439 adults with the line of discrimination between smokers $(\square)$ and non-smokers $(\times)$. The dashed lines are the limiting values of $1.6 \% \mathrm{COHb}$ and $73 \mu \mathrm{mol} S \mathrm{CN} / \mathrm{l}$.

Table 3 Cigarette consumption (cigarettes/day), carboxyhaemoglobin $(\mathrm{COHb})$, and plasma thiocyanate $(S C N)$ concentrations, and discriminant analysis $(z)$ predictions in subjects with contradictory biochemical test classifications

(a) COHb misclassifications when SCN predictions were correct

\begin{tabular}{llcl}
\hline Cigarettes/day & $\mathrm{COHb}(\%)$ & $S C N(\mu \mathrm{mol} / \mathrm{l})$ & $z$ \\
\hline 0 & 1.9 & 23.0 & Non-smoker \\
0 & 2.3 & 30.0 & Non-smoker \\
10 & 0.7 & 90.0 & Non-smoker \\
15 & 1.4 & 133.0 & Smoker \\
20 & 1.3 & 85.0 & Non-smoker \\
37 & 1.5 & 136.0 & Smoker \\
\hline
\end{tabular}

(b) SCN misclassifications when $\mathrm{COHb}$ predictions were correct

\begin{tabular}{|c|c|c|c|}
\hline Cigarettes/day & $\mathrm{COHb}$ & $S C N$ & $z$ \\
\hline 0 & 0.7 & $74 \cdot 0$ & Non-smoker \\
\hline 0 & $0 \cdot 8$ & $76 \cdot 0$ & Non-smoker \\
\hline 0 & 0.5 & $89 \cdot 0$ & Non-smoker \\
\hline 0 & $1 \cdot 2$ & $114 \cdot 0$ & Non-smoker \\
\hline 2 & $3 \cdot 4$ & $65 \cdot 0$ & Smoker \\
\hline 5 & $2 \cdot 5$ & 70.0 & Smoker \\
\hline 6 & $3 \cdot 7$ & 58.0 & Smoker \\
\hline 7 & $2 \cdot 4$ & $54 \cdot 0$ & Smoker \\
\hline 8 & $2 \cdot 0$ & $54 \cdot 0$ & Non-smoker \\
\hline 10 & $3 \cdot 4$ & $57 \cdot 0$ & Smoker \\
\hline 13 & 1.9 & $55 \cdot 0$ & Non-smoker \\
\hline 13 & $2 \cdot 1$ & $49 \cdot 0$ & Non-smoker \\
\hline 16 & $5 \cdot 3$ & $67 \cdot 0$ & Smoker \\
\hline 20 & $2 \cdot 6$ & 50.0 & Smoker \\
\hline 20 & $4 \cdot 8$ & $69 \cdot 0$ & Smoker \\
\hline 23 & $5 \cdot 6$ & $42 \cdot 0$ & Smoker \\
\hline 28 & $2 \cdot 5$ & 60.0 & Smoker \\
\hline 30 & 3.7 & $49 \cdot 0$ & Smoker \\
\hline 38 & $5 \cdot 6$ & $55 \cdot 0$ & Smoker \\
\hline 40 & 3.9 & $52 \cdot 0$ & Smoker \\
\hline
\end{tabular}

Table 4 The number of subjects in each class of daily cigarette consumption misclassified by predictions based on carboxyhaemoglobin $(\mathrm{COHb})$ or plasma thiocyanate (SCN) concentrations and on discriminant analysis (z)

\begin{tabular}{lllll}
\hline \multirow{2}{*}{$\begin{array}{l}\text { Smoking class } \\
\text { (cigarettes/day) }\end{array}$} & $\begin{array}{l}\text { Total No } \\
\text { in class }\end{array}$ & \multicolumn{2}{l}{ No misclassified } \\
\cline { 3 - 5 } \cline { 3 - 4 } & & COHb & SCN & $z$ \\
\hline $1-5$ & 11 & 6 & 9 & 6 \\
$6-15$ & 43 & 4 & 7 & 6 \\
$16-25$ & 108 & 2 & 5 & 2 \\
$26-35$ & 90 & & 2 & \\
$36-45$ & 75 & 1 & 2 & \\
$\geqslant 46$ & 33 & & & \\
\hline
\end{tabular}

Table 5 Sex, daily cigarette consumption (cigarettes per day), and carboxyhaemoglobin ( $\mathrm{COHb}$ ) and plasma thiocyanate (SCN) levels of smokers misclassified by all tests including $z$

\begin{tabular}{llll}
\hline Sex & Cigarettes/day & $\mathrm{COHb}(\%)$ & SCN $(\boldsymbol{\mu m o l} / \mathrm{l})$ \\
\hline F & 1 & 0.5 & 42 \\
F & 4 & 0.7 & 42 \\
F & 5 & 1.5 & 45 \\
F & 8 & 0.3 & 53 \\
F & 8 & 1.3 & 33 \\
F & 16 & 1.5 & 66 \\
M & 1 & 1.1 & 47 \\
M & 3 & 1.1 & 56 \\
M & 5 & 1.3 & 70
\end{tabular}


being used to assist people to stop smoking nicotine and its metabolite cotinine are obviously inappropriate for monitoring withdrawal.

Carboxyhaemoglobin and thiocyanate are less specific indicators of smoking. Carbon monoxide is produced endogenously from haem compounds and raised levels of carboxyhaemoglobin may occur in haemolytic anaemias. ${ }^{12}$ Occupational exposure to environmental carbon monoxide will also raise the concentration. ${ }^{13}$ There are more exogenous sources of thiocyanate and diet is probably the main reason for the wide variations of this anion in the plasma, urine, and saliva of non-smokers. ${ }^{14}$ Smoking, however, remains the single most important cause of high carboxyhaemoglobin and thiocyanate concentrations in blood (table 1). Pyrolysis of tobacco produces up to $5 \%$ carbon monoxide and $0.16 \%$ hydrogen cyanide in the gas phase, as well as organic cyanide compounds (nitriles-about $1 \mathrm{mg}$ a cigarette) in the particulate phase. Most of the carbon monoxide and hydrogen cyanide (and its compounds) is absorbed through the lungs. In addition, some hydrogen cyanide is absorbed through the buccal and nasal mucosa. Both the free hydrogen cyanide and that released during the metabolism of the nitriles is converted to thiocyanate by the mitochondrial enzyme rhodanese.

Carboxyhaemoglobin and plasma thiocyanate each identified correctly the group to which over $90 \%$ of our subjects belonged (table 2). These results are similar to those reported by $\operatorname{Vogt}^{5}$ and better than those of Cohen and Bartsch. ${ }^{15}$ The very high levels of carboxyhaemoglobin $(\geqslant 6 \%)$ and thiocyanate $(\geqslant 200 \mu \mathrm{mol} / \mathrm{l})$ found in some of the non-smoking subjects in the latter study make it possible that some of those claiming to be nonsmokers were in fact smokers; this would explain the reduced specificity and sensitivity of the tests in this case.

In nine of our smoking subjects both carboxyhaemoglobin and thiocyanate levels were within the non-smoking range (table 5). Most of these people consumed relatively few cigarettes, while others might have been non-inhalers. These factors may account for the atypical results and no biochemical test is likely to identify such individuals.

The object of using discriminant analysis was to weight and linearly combine the discriminating variables (carboxyhaemoglobin and thiocyanate) in such a manner that the groups (smokers and nonsmokers) are forced to be as statistically distinct as possible. The chief benefit of this analysis was in deciding the group to which subjects with contradictory carboxyhaemoglobin and thiocyanate classifications belonged. There were 26 such subjects and 21 of these were successfully grouped with the help of the function $\mathrm{z}$ (table 3). But as $\mathrm{z}$ achieved only a marginally better overall classification than that obtained with carboxyhaemoglobin there appears to be no real advantage in making both biochemical measurements. Indeed, thiocyanate estimation is a more complicated procedure than the procedure for determining carboxyhaemoglobin levels with the $\mathrm{CO}-O x i m e t e r ;$ and the extra expense, analysis time, and labour required in measuring thiocyanate cannot be justified. The one major advantage of thiocyanate derives from the long half-life (14 days) of this anion in plasma. ${ }^{16}$ Carboxyhaemoglobin, on the other hand, has a half-life of only 3.1 hours in subjects engaged in light activity, increasing to 6.9 hours during sleep. ${ }^{17}$ Carboxyhaemoglobin is therefore more susceptible to the effects of short-term changes in smoking habits. Thus if subjects stop smoking for 24 hours before blood sampling carboxyhaemoglobin levels can fall to within the non-smoking range, whereas the plasma thiocyanate concentration will be virtually unaffected.

The cut-off points used in this study may not be applicable to studies in which different analytical procedures are used. There are no standardised techniques for measuring either carboxyhaemoglobin or thiocyanate and systematic errors between different methods may arise. ${ }^{18} 19$ Published means for these measures in non-smokers show considerable variation ${ }^{232021}$ and each laboratory must therefore determine its own normal values. The $\mathrm{CO}$ Oximeter gave results with excellent repeatability ${ }^{\circ}$ and is easy to use and rapid (an analysis takes only one minute). Our thiocyanate method also has a good precision; routine analysis of two batches of pooled plasma over three months gave means and standard deviations of $46 \cdot 1 \pm 2 \cdot 4$ and $117 \cdot 8 \pm 6 \cdot 4$ $\mu \mathrm{mol} \mathrm{SCN} / 1$ plasma $(n=50)$. This analysis, however, is slower (only 20 plasma samples are processed in an hour) and requires costly reagents.

In conclusion, our results indicate that the ability to distinguish between smokers and non-smokers is only marginally enhanced by combining carboxyhaemoglobin and thiocyanate measurements. In most instances carboxyhaemoglobin estimation alone is sufficient to decide whether a person is smoking. Measurement of thiocyanate, however, may be preferable, because of its longer half-life, in people who show erratic smoking patterns or are making intermittent attempts to stop smoking.

We are grateful to the Joint Research Board of St Bartholomew's Hospital and to the Medical Research Council for financial support. 


\section{References}

' Delarue NC. A study in smoking withdrawal. Can J Pub Health 1973;64:5-19.

${ }^{2}$ Ohlin P, Lundh B, Westling H. Carbon monoxide blood levels and reported cessation of smoking. Psychopharmacology 1976;49:263-5.

${ }^{3}$ Sillett RW, Wilson MB, Malcolm RE, Ball KP. Deception among smokers. Br Med J 1978;ii:1185-6.

4 Wilcox RG, Hughes J, Roland J. Verification of smoking history in patients after infarction using urinary nicotine and cotinine measurements. Br Med J 1979;ii:1026-8.

${ }^{5}$ Vogt TM, Selvin S, Widdowson G, Hulley SB. Expired air carbon monoxide and serum thiocyanate as objective measures of cigarette exposure. Am J Pub Health 1977;67:545-9.

- Jarvis MJ, Russell MAH, Saloojee Y. Expired air carbon monoxide: a simple breath test of tobacco smoke intake. $\mathrm{Br} \mathrm{Med} \mathrm{J}$ 1980;281:484-5.

' Casapieri P, Scott R, Simpson EA. The determination of cyanide ions in waters and effluents by an auto-analyser procedure. Anal Chim Acta 1970;49:188-92.

${ }^{8}$ Ellerker R, Collinson B. Use of an autoanalyser for sewage works' analyses. Technicon Symposium on Automation in Analytical Chemistry. London: Technicon, 1971:127-38.

9 Armitage P. Statistical methods in medical research. Oxford: Blackwell Scientific Publications, 1973.

${ }^{10}$ Russell MAH, Feyerabend C. Blood and urinary nicotine in non-smokers. Lancet 1975;i:179-81.

"Williams CL, Eng A, Botvin GJ, Hill P, Wynder EL. Validation of students' self-reported cigarette smoking status with plasma cotinine levels. Am J Pub Health 1979;69:1272-4.
12 White P, Coburn RF, Williams WJ, Goldwein MI, Rother ML, Shafer BC. Carbon monoxide production associated with ineffective erythropoiesis. J Clin Invest 1967;46:1986-98.

${ }^{13}$ Stewart RD, Baretta ED, Platte LR, Stewart EB, Kalbfleisch JH, Yserloo BV, Rimm AA. Carboxyhaemoglobin levels in American blood donors. JAMA 1974;229:1187-95.

14 Vesey CJ. Thiocyanate and cigarette consumption. In: Greenhalgh RM, ed. Smoking and arterial disease. Bath: Pitman Medical, 1981:107-18.

is Cohen JD, Bartsch GE. A comparison between carboxyhaemoglobin and serum thiocyanate determinations as indicators of cigarette smoking. Am J Pub Health 1980;70:284-6.

${ }^{16}$ Pettigrew AT, Fell GS. Simplified colorimetric determination of thiocyanate in biological fluids and its application to investigation of the toxic amblyopias. Clin Chem 1972;18:996-1000.

${ }^{17}$ Castleden CM, Cole PV. Variations in carboxyhaemoglobin levels in smokers. Br Med J 1974;iv:736-8.

18 Commins BT, Berlin A, Langevin M, Peal JA. Intercomparison of measurement of carboxyhaemoglobin in different European laboratories and establishment of the methodology for the assessment of $\mathrm{COHb}$ levels in exposed populations. Luxembourg: Health and Safety Directorate, Commission of the European Communities, 1977.

19 Maliszewski TF, Bass DE. "True" and "apparent" thiocyanate in body fluids of smokers and non-smokers. J Appl Physiol 1955;8:289-91.

${ }^{20}$ Stoa KF. Studies on thiocyanate in serum. Bergen: AS John Griegs, 1957:74-9. (Universitetet i Bergen Arbok, Medisinsk rekke 2.)

${ }^{21}$ Butts WC, Kuehneman M, Widdowson GM. Automated method for determining serum thiocyanate to distinguish smokers from non-smokers. Clin Chem 1974;26:493-5. 